\title{
Herbal Products and Supplements in Palliative Care ${ }^{+}$
}

\section{Burcak Deniz Dedeoglu}

Zade Vital Pharma, Chemicals \& Food Inc., 34775 Istanbul, Turkey; ddedeoglu@zade.com.tr

+ Presented at the 3rd International conference on Natural Products for Cancer Prevention and Therapy, Kayseri, Turkey, 18-20 December 2019.

Published: 27 December 2019

\begin{abstract}
Conventional medicine focuses mostly on the diagnosis and treatment of disease which is the acute localized problem in healthy body. On the other hand, chronic diseases are functional disorders in physiological processes. Therapeutic goal is not to treat the disease but heal the whole unhealthy body. The environment, changed with the industrial development, created a new human model, that suffering from stress and biologic damage. And that brought us a new terminology; epigenetics. Today, we are aware of that; the body would help itself for healing if we support. Up to date oncology approach, immuno-oncology is the study and development of treatments that take advantage of the body's immune system to fight cancer. Nature is the main source to support immune system. There is not enough reliable scientific evidence to use it as a treatment for cancer. $\mathrm{Bu}$ it is already a part of supportive and palliative care. Supportive treatment is not secondary to cancer. Scientific studies have shown that humans and other organisms are able to adapt better and survive longer when using these adaptogenic herbs. Treating chemo side effects naturally is a common practice these days and it is supported by strong scientific evidence.
\end{abstract}

Keywords: palliative care; natural products; supplement; immune modulation; adaptogenic herbs

(C) 2019 by the authors. Licensee MDPI, Basel, Switzerland. This article is an open access article distributed under the terms and conditions of the Creative Commons Attribution (CC BY) license (http://creativecommons.org/licenses/by/4.0/). 